\title{
Influência da avaliação comportamental de consumo do idoso na ergonomia organizacional de supermercados
}

\section{Influence of the elderly consumers behavioral evaluation in the organizational supermarket ergonomics}

\author{
Marcelo Pereira Demilis ${ }^{1}$ \\ Alexandre Amorim dos Reis ${ }^{2}$ \\ Flávio Anthero Nunes Vianna dos Santos ${ }^{3}$
}




\section{Resumo}

O usuário e suas limitações, necessidades e vontades devem ser considerados ao longo do desenvolvimento de um projeto e na execução de um serviço para a garantia de satisfação do público-alvo. Assim questiona-se a influência do entendimento comportamental do público idoso na contribuição no estabelecimento da ergonomia organizacional dos supermercados. Por essa razão, o objetivo deste artigo é de utilizar da metodologia quantitativa para realizar uma pesquisa bibliométrica, por meio da base de dados do portal de periódicos CAPES, sobre o comportamento dos idosos sob a ótica de serviços de supermercados; e através de análise qualitativa correlacionar os estudos levantados com a ergonomia organizacional destes estabelecimentos de varejo de alimentos, e verificar a influência da análise dos aspectos comportamentais, limitações, necessidades, vontades, desse público sênior, na promoção dos serviços de supermercado e meIhoria da experiência de compra. Como conclusão, foi perceptível que, com a ascensão da valorização da experiência vivenciada pelo consumidor, o entendimento do usuário idoso em vários níveis, não se restringindo apenas ao nível da capacidade física, se mostrou um grande agregador para o desenvolvimento e ou melhoria da experiência de consumo dentro de um supermercado.

Palavras-chave: Comportamento; Idoso; Consumo; Supermercado; Ergonomia Organizacional.

\section{Abstract}

The user and his limitations, needs and wants must be considered during the design development and implementation of a service to guarantee satisfaction of the audience. That is why it is questioned the influence of the behavioral understanding of the elderlyon the contribution for the establishment of groceries organizational ergonomics. Therefore , the aim of this article is to use quantitative methodology to perform a bibliometric search through the database of the portal CAPES journals, about the behavior of older people from the grocery services perspective, and through qualitative analysis correlate the selected studies with the supermarket organizational ergonomics, and verify the influence of the analysis of behavioral aspects, limitations, needs, wants, of the senior public, on the groceries services providing and the improving of shopping experiences. As conclusion, it was noticeable that, with the rise of valor given on a good lived consumer experience, the understanding of the elderly users in many ways, not only restricted to the physical ability level, proved that it is a great aggregator for the development and improvement of consumption experience in a grocery.

Key-words: Behaviour; Elderly; Consumption; Grocery; Organizational Ergonomics.

ISSN: 2316-7963

1Doutorando em Design, UFSC (marcelodemilis@gmail.com)

2 Doutor em Engenharia, UDESC

${ }^{3}$ Doutor em Engenharia, UDESC 


\section{Introdução}

O Brasil está envelhecendo e segundo Solomon (2002) a longevidade da população aumentou devido a avanços na medicina, assim como com o desenvolvimento do país e avanços tecnológicos. Com base em estatísticas do IBGE (2009), estima-se que o percentual de brasileiros com mais de 60 anos de idade, até o ano 2030, representará 18,7\% da população. Em 2010 já existiam mais de 19,3 milhões de pessoas acima dessa idade no país e calcula-se que, em 2006 , cerca de $R \$ 8,8$ bilhões mensais passaram pelas mãos desses potenciais consumidores (STREHLAU; BACHA; LORA, 2006), o que representou $4,4 \%$ do PIB do Brasil naquele ano.

Contudo, atualmente existe uma enorme defasagem de produtos e serviços especializados que atendem efetivamente o consumidor idoso. A real potencialidade desse público de consumidores no Brasil, devido ao aumento da expectativa de vida no país e ascensão econômica, revela a necessidade do desenvolvimento de um olhar clínico sobre esta parcela da população. E acompanhando a carência de olhar sobre o público da terceira idade, está a falta de estudos atuais que concernem este público e suas formas de consumo, mais especificamente como consomem serviços. Empresas que fornecem serviços, que acabam sendo usados também por pessoas de terceira idade, muitas vezes não levam em consideração reais necessidades, vontades e condições desses indivíduos com a idade mais avançada. Um exemplo dessa realidade são os supermercados. Conforme Petermans e Van Cleempoel (2010), pesquisas sobre experiências de compra dos consumidores idosos são relativamente raras e se concentram em experiências de compras, comportamento do patronato, bem como a identificação de atributos que idosos valorizam.

A Ergonomia é definida como a adaptação do trabalho ao homem (lida 1990). Para a realização dos seus objetivos, ela estuda uma diversidade de fatores relacionados ao homem, à máquina, ao ambiente, à informação, à organização, e as consequências da tarefa na saúde do executor. Porém, os estudos ergonômicos não precisam se limitar apenas ao ambiente de trabalho. Eles podem ter um viés mais amplo em que se estudam os movimentos humanos fora desse ambiente, desempenhando inúmeras atividades, levando sempre em consideração os aspectos humanos do indivíduo.

Com base na ABERGO - ASSOCIAÇÃO BRASILEIRA DE ERGONOMIA, a Ergonomia se divide em três especialidades: Ergonomia física, Ergonomia cognitiva e Ergonomia Organizacional. Para efeitos desse artigo, será abordada a Ergonomia Organizacional por ela se envolver processos e estruturas organizacionais e enquadrar melhor todo universo do objeto de estudo aqui pautado, que é o supermercado e o reflexo do comportamento de consumo do idoso no serviço prestado por este tipo de estabelecimento de varejo.

Por ergonomia organizacional entende-se como a otimização dos sistemas sociotécnicos. Sendo sistemas sociotécnicos aqueles que incluem sistemas técnicos, processos operacionais e pessoas que usam e interagem nesse sistema e são regidos por políticas e regras organizacionais. A Ergonomia Organizacional ou macroergonomia parte do pressuposto que todo o trabalho ocorre no âmbito de organizações e tem como objetivo potencializar os sistemas existentes na organização, incluindo a estrutura, políticas e processos. 
Ilda (1990) aponta que para uma atividade ocorrer de forma satisfatória e com a eficiência máxima, um sistema homem-máquina deve ser planejado como um todo, com o ser humano completando a máquina, sendo esta toda a ajuda material que o usuário possa utilizar no seu trabalho, englobando produto, equipamento e ambiente. Desta maneira, é perceptível a possibilidade de aplicação dos conhecimentos da Ergonomia para avaliações de tarefas do usuário em diversos níveis, seja físico, cognitivo ou organizacional dentro do ambiente do supermercado, com intuito de entender como o indivíduo executa uma tarefa, o porquê de estar executando daquela maneira, se é preciso melhorá-la e como realizar essa melhora. Como resultados desses levantamentos, análises e correções têm a melhora da atividade como um todo (em eficiência, eficácia, satisfação).

Se um produto, equipamento ou ambiente, segundo lida (1990), não atender aos aspectos humanos e se tornar de difícil operação, consequentemente, outros mecanismos humanos serão necessários para executar a tarefa, e o custo decorrente resultará em perda de eficiência. Desta forma, o ato de projetar deve estar de acordo com os aspectos humanos para garantir a eficiência.

Jordan (1998) define o termo "usabilidade" como o quanto é fácil utilizar um determinado produto. Aqui se entende por produto, segundo Santos (2000), tudo aquilo que sai de um processo produtivo, ou seja, pode tanto ser um serviço quanto um bem de consumo. Jordan (1998) ainda ressalta que o fato de um produto ser facilmente usado por uma pessoa não significa necessariamente que poderá ser utilizado da mesma forma por outro indivíduo. Projetar tendo a usabilidade como base, significa desenvolver produtos especificamente para aqueles indivíduos que irão utilizar o produto em definições de design, ergonomia, usabilidade, interação. Logo, é de extrema importância possuir conhecimento e compreensão sobre quem são os usuários finais do produto e quais são as suas respectivas características, como no caso do tema abordado, entender o usuário idoso, por quem o serviço de supermercado poderá vir a ser usado.

A satisfação de consumo dos consumidores mais velhos não provém apenas do ato de consumir para a obtenção de bens tangíveis, mas de consumir, enquanto procuram experiências intangíveis, como sentir-se bem-vindos em um supermercado, ter uma conversa amigável ou apreciar o ambiente, apreciar um bom serviço (Kim, Kang e Kim, 2005 ; Sherman, Schiffman e Mathur, 2001). Burt e Gabbott (1995) mostram que os compradores idosos também podem se envolver em compras como forma de socializar com os seus amigos, além do ato de consumir por si só. Assim, Petermans e Van Cleempoel (2010) apontam que as lojas de varejo, quando devidamente concebidas para satisfazer as necessidades e desejos do mercado das pessoas anciãs, podem aumentar fortemente experiências de compras deste segmento de consumidores.

A partir destas percepções e partindo do pressuposto de que o usuário, suas necessidades e vontades devem ser considerados ao longo do desenvolvimento de um projeto e na execução de um serviço para a garantia de satisfação do público-alvo, questiona-se a influência do entendimento da forma de consumo, necessidades e vontades do público idoso na contribuição no estabelecimento da ergonomia organizacional dos supermercados. Desta forma objetivou-se com este artigo fazer o levantamento de trabalhos relacionados ao comportamento idoso como consumidor em estabelecimentos de varejo e as saídas geradas através desses estudos. Com base 
nessas saídas, fez-se um confrontamento entre elas com intuito de averiguar a importância, influência e aplicações dos dados levantados na ergonomia organizacional de um estabelecimento de varejo.

\section{METODOLOGIA}

Quanto à metodologia este artigo possui a natureza básica, ou seja, segundo Silva e Menezes (2005) seu objetivo é gerar conhecimentos novos úteis para o avanço da ciência, conhecimentos estes que envolvem verdades e interesses universais. Quanto à forma de abordagem, este artigo é quantitativo e qualitativo, pois inicia com uma abordagem relacionada à pesquisa bibliométrica e segue com a análise qualitativa a partir da interpretação dos artigos selecionados para a pesquisa, dando-lhes significados e características. Essa explanação se baseia nas percepções relacionadas ao envelhecimento da população, a potencialidade do consumidor idoso, seus comportamentos, limitações, necessidades e vontades, sob a perspectiva do serviço de supermercado. Por fim, faz-se a associação das interpretações dos artigos com a ergonomia organizacional dos supermercados e como ela pode ser influenciada com base nesses estudos.

A parte bibliométrica deste artigo foi elaborada com base em Pritchard (1969), e buscou-se identificar artigos que tratassem, sob a ótica do serviço de supermercado, do comportamento de consumo do idoso, suas limitações, necessidades e vontades. A coleta de dados para a investigação empírica foi feita inicialmente

através de pesquisa online, através do portal de periódicos científicos CAPES. Utilizou-se a combinação termos de busca "elderly", "bahaviour" e "supermarket", atribuindo alguma variações aos termos como "older", "retail" e "grocery" ou refinando a busca por "older consumers", "consumers", "shopping" e "food". Como resultado, se obteve catorze resultados como demonstra a tabela abaixo:

Tabela1: Resultados da pesquisa bibliométrica na base de Periodicos da CAPES

\begin{tabular}{cccc}
\hline COMBINAÇÕES DE TERMOS & 10 REFINAMENTO & 20 REFINAMENTO & RESULTADO \\
\hline Older + behaviour + supermarket & Elderly & Consumers & 1 \\
Older + behaviour + supermarket & Older Consumers & (-)Pharmaceuticals & 9 \\
Elderly + behaviour + retail & Older Consumers & Food & 2 \\
Elderly + behaviour + grocery & Shopping & - & 2 \\
Total & & 14 \\
\hline
\end{tabular}

Fonte: Elaborado pelos autores, com base na pesquisa realizada.

A partir dos resultados, fez-se uma seleção qualitativa dos artigos que realmente apresentavam conteúdo que estava dentro da proposta apresentada pelos autores e que teriam maior contribuição para o estudo. Os artigos são apresentados a seguir. 
Influência da avaliação comportamental de consumo do idoso na ergonomia organizacional de supermercados

\section{COMPORTAMENTO DO CONSUMIDOR IDOSO EM SUPERMERCADOS}

Nesta seção serão abordados os temas centrais dos cinco artigos selecionados segundo a pesquisa apresentada anteriormente, para averiguar sua relação com a ergonomia organizacional de um estabelecimento de varejo com base no entendimento do comportamento de consumo dos idosos, comportamentos sociais necessidades e vontades. Para melhor visualizar características desses artigos, foi desenvolvida uma tabela comparativa dos artigos (Tabela 2), destacando locais de estudo, palavras-chave e objetivos:

Tabela 2: Comparativo de artigos

\begin{tabular}{|c|c|c|c|}
\hline ARTIGO & LOCAIS DE ESTUDO & PALAVRAS-CHAVE & OBJETIVO DO ESTUDO \\
\hline $\begin{array}{c}\text { Petermans e } \\
\text { Van Cleempoel } \\
\text { (2010) }\end{array}$ & $\begin{array}{l}\text { Alemanha, Áustria } \\
\text { e Bélgica } \\
\text { (perspectiva } \\
\text { europeia) }\end{array}$ & - & $\begin{array}{l}\text { Discutir as necessidades e vontades físicas e } \\
\text { sociais dos consumidores idosos no mercado, e } \\
\text { apresentar estudos de caso de duas lojas de } \\
\text { varejo de alimentos europeus, que foram } \\
\text { projetados para atender a essas preocupações. }\end{array}$ \\
\hline $\begin{array}{l}\text { Meneely, Burns } \\
\text { e Strugnell } \\
\text { (2009a) }\end{array}$ & Irlanda do Norte & $\begin{array}{l}\text { Older consumers; } \\
\text { Food products; } \\
\text { Retailing; Consumer } \\
\text { behavior; Shopping; } \\
\text { Northern Ireland }\end{array}$ & $\begin{array}{l}\text { Analisar as mudanças no comportamento } \\
\text { alimentar dos consumidores de varejo em } \\
\text { relação à variável demográfica de idade, com } \\
\text { base na população Idosa. }\end{array}$ \\
\hline $\begin{array}{l}\text { Yin, Pei e } \\
\text { Ranchhod } \\
\text { (2012) }\end{array}$ & Reino Unido & $\begin{array}{l}\text { Elderly consumers; } \\
\text { Shopping experience; } \\
\text { Ethnographic } \\
\text { method; Design; IT; } \\
\text { Elderly people; } \\
\text { Consumers, Older } \\
\text { consumers, } \\
\text { Supermarkets }\end{array}$ & $\begin{array}{l}\text { Investigar as dificuldades e os desafios } \\
\text { enfrentados pelos consumidores idosos nos } \\
\text { supermercado, a fim de formar insights sobre } \\
\text { possíveis formas de aplicação de suporte de TI } \\
\text { e soluções de design dentro do serviço de } \\
\text { supermercados para os consumidores mais } \\
\text { velhos. }\end{array}$ \\
\hline $\begin{array}{l}\text { Meneely, Burns } \\
\text { e Strugnell } \\
\text { (2009b) }\end{array}$ & Irlanda do Norte & $\begin{array}{l}\text { Older consumer, } \\
\text { Food shopping, } \\
\text { Access, Issues, } \\
\text { Satisfaction }\end{array}$ & $\begin{array}{l}\text { Determinar o comportamento e experiência } \\
\text { dos consumidores mais velhos na Irlanda do } \\
\text { Norte durante o processo de aquisição de } \\
\text { alimentos e fazer algumas recomendações para } \\
\text { minimizar constrangimentos do consumidor } \\
\text { idoso. }\end{array}$ \\
\hline Kohijoki (2011) & Finlândia & $\begin{array}{l}\text { Accessibility, Aging, } \\
\text { Disadvantaged } \\
\text { consumers, } \\
\text { The elderly, } \\
\text { Grocery shopping } \\
\text { behaviour }\end{array}$ & $\begin{array}{l}\text { Descobrir se o envelhecimento dos } \\
\text { consumidores teve efeito sobre o } \\
\text { comportamento de compras e a acessibilidade } \\
\text { dos serviços de supermercado, e se os idosos } \\
\text { são consumidores desfavorecidos. }\end{array}$ \\
\hline
\end{tabular}

Fonte: Elaborado pelos autores, com base na pesquisa realizada 
O primeiro artigo de Petermans e Van Cleempoel (2010) trata sobre a perspectiva europeia de se projetar um ambiente de loja de varejo voltado para o público idoso, apresentando dois cases de supermercados europeus o "Adeg Aktiv Markt 50+" e o "Kaiser's Generations Market". Os autores discutem as necessidades físicas e sociais dos consumidores idosos e o quanto designers devem dar maior atenção às idiossincrasias da terceira idade.

Petermans e Van Cleempoel (2010) apontam ainda que não apenas os aspectos físicos são importantes, mas também aspectos sociais são considerados essenciais para criar um serviço que seja eficiente, amigável e esteticamente agradável para garantir a satisfação do público mais velho. Os idosos querem se sentir bem vindos e querem vivenciar experiências que vão além do consumo do tangível, transpondo a barreira da tangibilidade. Vale salientar que o comportamento dos idosos deve ser analisado ponderando também, não a idade cronológica, mas sim a idade psicológica do indivíduo, pois essa sim segmenta melhor as diferentes faixas de idosos e facilita na identificação de padrões de comportamento, tendo em vista que o envelhecimento é particular de cada indivíduo e é influenciado por diversos fatores.

Sob o espectro da Ergonomia Organizacional, este primeiro artigo leva a crer que compreender quem são os consumidores da loja e suas características funcionais, sociais e emocionais específicas, do que gostam e não gostam no serviço pode ajudar os varejistas e gerentes no desenvolvimento de uma estratégia da própria marca da loja de varejo. O estudo do comportamento dos idosos pode também ajudar designers a projetar supermercados de tal forma que os compradores mais velhos estejam à vontade com o serviço prestado e queiram voltar ao estabelecimento e usufruir novamente do serviço. Em um supermercado, para público mais velho, organização, funcionalidade, estética, acessibilidade são tão valorizadas quanto às experiências oferecidas pelo estabelecimento. Petermans e Van Cleempoel (2010) afirmam que as melhorias funcionais e sociais em supermercados podem resultar em consumidores fiéis, além de que alterações de design podem resultar em um ambiente de varejo adequado, especificamente concebido, que presta especial atenção à aplicação de uma abordagem social adequada, podem aumentar fortemente experiências de compras para o mercado maduro.

No segundo artigo, Meneely, Burns e Strugnell (2009a) defendem que compreensão do comportamento do consumidor idoso permite que os provedores de serviços segmentem seus clientes base e foque em grupos específicos com estratégias projetadas para satisfazer as necessidades desses grupos dentro de um estabelecimento fornecedor de alimentos em varejo, pois o comportamento varia de acordo com as diferentes faixas de idade compreendidas no macro grupo "idosos". Acredita-se que a introspecção e compreensão de como os consumidores interagem e avaliam uma oferta de varejo ajudam a melhorar o fornecimento do serviço e a satisfação do cliente.

Por isso, por meio de seu estudo baseado em questionários aplicados com público idoso da Irlanda do Norte, os autores buscaram analisar as mudanças de comportamento em usuários de estabelecimentos de varejo de alimentos com relação às mudanças demográficas de idade com base na população mais velha. Características e informações como estilo de vida, tipo de relacionamento, tipo e proximidade 
de estabelecimento frequentado, habilidade de dirigir, tipo de transporte utilizado, o que compram e com que frequência vão a mercados locais, nível de planejamento de compras, nível de dificuldade de acesso e localização da loja, satisfação em comprar, valorização de ofertas, percepção de conveniência, confiança nutricional, foram levadas em consideração.

Meneely, Burns e Strugnell (2009a) concluíram que conforme a idade aumenta, percebe-se a mudanças no consumo do serviço fornecido por supermercados, bem como mudanças no comportamento relacionado a alimentos. Idosos frequentam menos estabelecimentos diferentes, dão preferência para as lojas locais, se preocupam mais com o valor nutricional dos alimentos, têm dificuldade para acessar os sites de varejo, apresentam maiores dificuldades ao cozinhar e desenvolvem um maior apresso pelas compras e a socialização promovida por estas. Desta maneira, varejistas devem levar em consideração os aspectos físicos e comportamentais que mudam com o avanço da idade no intuito de melhorar fatores organizacionais do empreendimento e prover um serviço que melhor satisfaça o público idoso.

No terceiro artigo selecionado Yin, Pei e Ranchhod (2012) em seu estudo investigaram as dificuldades e problemas encontrados pelos idosos em supermercados no intuito de gerar insights sobre possíveis formas de aplicação de suporte por meio de TI (tecnologia da informação) e soluções de design para o serviço de supermercados voltados para consumidores mais velhos. Por meio de abordagens etnográficas, observações diretas e, em um segundo momento, entrevistas semiestruturadas, os autores coletaram informações quanto ao comportamento desse público, bem como suas experiências de compra. Os resultados apresentados indicaram uma série de áreas onde os consumidores seniores enfrentam dificuldades e que precisam ser melhoradas, como gôndolas e acesso a produtos (alturas), orientação dentro da loja (sinalização e layout), suporte ao cliente, dificuldade de leitura de informações de produtos, entre outros problemas.

O entendimento do comportamento do público sênior, junto com a exploração de suas experiências por meio de uma abordagem etnográfica, ainda são ações pouco usadas, mas que enriquecem muito a leitura de padrões de comportamento, auxiliando que varejistas e designers apresentem soluções de serviços mais assertivos e satisfatórios.

Há tentativas limitadas ao uso de uma abordagem etnográfica para explorar experiências de compras dos consumidores idosos no Reino Unido. Os estudos existentes não olham para os aspectos práticos de problemas comerciais cotidianos enfrentados por este segmento da população. Este tipo de abordagem adiciona valor à compreensão dos varejistas dos padrões de comportamento deste segmento de clientes, ao mesmo tempo em que oferece soluções para determinados problemas em diversos níveis organizacionais do estabelecimento, desde sinalização a indicações para utilização de TI.

Meneely, Burns e Strugnell (2009b) neste outro artigo defendem a mudança de comportamento das pessoas com relação a necessidades, desejos e capacidades conforme o avanço da idade. Contudo a necessidade básica de alimento é constante, porém as mudanças do indivíduo associadas ao envelhecimento podem comprometer o acesso aos alimentos e consequentemente a sua nutrição e saúde. A partir desse 
pressuposto, se sustenta a teoria dos autores de que é necessário fornecer aos consumidores mais velhos um ambiente mais favorável, proporcionando oportunidades adequadas para acessarem produtos alimentares.

Sua pesquisa procurou determinar padrões de comportamento e experiência dos consumidores mais velhos na Irlanda do Norte durante o processo de aquisição de alimentos e buscou gerar recomendações para minimizar constrangimentos do consumidor sênior. Foram feitas coletas de dados com base em experiências descritas em quatro focus groups com grupos consistidos de oito a dez consumidores com idade superior a 60 anos. Cada grupo de foco consistia de oito a dez adultos e foi realizado em um ambiente social familiar.

Meneely, Burns e Strugnell (2009b) demonstram, por meio dos resultados qualitativos e quantitativos obtidos, que foram identificados padrões de compra e motivações que impulsionam as decisões de compra nessa faixa etária. Foi possível identificar frequência em que utilizam serviço de supermercados, a dependência da ajuda por parte de alguns clientes em acessar as lojas, problemas de layout, valorização de funcionários simpáticos e prestativos, valorização de estabelecimentos que fornecem serviços secundários como correios e farmácia. Assim, com base nessas observações, foi possível a proposição aos varejistas de alimentos e aos responsáveis organizacionais, melhorias, como por exemplo, intensificação de assistência aos idosos no interior da loja, aprimoramentos na rotulagem de produtos, entre outras soluções, na tentativa de superar os problemas e limitações que restringem o acesso aos alimentos pelos consumidores idosos.

Já Kohijoki (2011) em seu artigo, observam que a sociedade ocidental está envelhecendo e enfrentando algumas particularidades, como a dos baby-boomers chegando à aposentadoria, e consequentemente aumentando o número de consumidores idosos. Com essa percepção realizaram um estudo de característica longitudinal (avaliação de variações de características ao longo do tempo) que considerasse a acessibilidade de idosos finlandeses a serviços de supermercados por meio de análise de dados coletados em família da Finlândia entre os anos de 2001 e 2006.

Os autores buscaram analisar a influência do envelhecimento e as limitações oriundas desse processo no comportamento de compra em um supermercado. Assim, puderam perceber que a maioria dos idosos não experienciam dificuldades significativas na acessibilidade, mas por outro lado apresentaram problemas em lidar com o transporte das compras devido suas limitações físicas. Também foi reforçada com este estudo, a busca desses consumidores sêniores por produtos e serviços que satisfaçam as suas necessidades, isto é, que levem suas particularidades em consideração.

Trazendo para o contexto brasileiro, onde a acessibilidade de um modo geral não é bem resolvida, é provável que esse público enfrentasse maiores dificuldades de acesso, 0 que demandaria um maior peso na ergonomia organizacional do estabelecimento.

\section{DISCUSSÃO}

Todos os estudos analisados, em grande parte dos seus respectivos processos, tiveram coletas de dados de ordem qualitativa, visto que as informações transmitidas tinham caráter descritivo e ou empírico. Por se tratarem de dados subjetivos, de- 
pendentes das interpretações dos consumidores e dos pesquisadores, foram utilizados métodos menos rígidos e que dão margem para maior riqueza de informações e percepções, como pesquisas etnográficas, focus groups, entrevistas semiestruturas. Estudos antigos existentes dão enfoque apenas em fatores quantitativos, não olham o idoso e suas necessidades como centro, deixando de lado aspectos práticos de problemas comerciais cotidianos enfrentados por este segmento da população. $O$ tipo de abordagem apresentado nos artigos aqui analisados adiciona valor à compreensão dos varejistas dos padrões de comportamento deste segmento de clientes, ao mesmo tempo em que oferece soluções para determinados problemas em diversos níveis organizacionais do estabelecimento.

O comportamento dos idosos muda com o avanço das idades. Não se deve observá-los com um grande grupo, é preciso segmenta-los em pequenos grupos para melhor entende-los e poder identificar padrões de consumo dentro destes segmentos. A grande maioria das pessoas com mais de 60 anos quer aproveitar a vida enquanto pode, quer ficar ativo, continuar a consumir, e começar a desfrutar de experiências com novas tecnologias (Balazs, 1994). As pessoas com mais de 60 anos apresentam uma maior tendência para se aposentar mais cedo e, assim ter mais tempo para o lazer, utilizando-o para compras e gastos (Petermans e Van Cleempoel 2010). Idosos, segundo os autores dos artigos, valorizam os aspectos práticos da qualidade do produto e facilidade de navegação no ambiente do supermercado e dão valor para a melhoria da experiência de compra, variedade e proximidade a outros serviços, isto é, dão valor quando o estabelecimento oferece serviços complementares como farmácia, caixa eletrônico, etc. Também dão valor a aspectos sociais proporcionados, isto é, interações, seja com colaboradores, conhecidos, ou amigos. Assim, é devido à boa experiência vivida, que utilizam o serviço novamente e se fidelizam ao empreendimento.

Desta forma, alguns aspectos observados nas pesquisas com relação a comportamentos e requisitos de projetos são apontados na tabela a seguir:

Tabela 2: Requisitos de projeto

\begin{tabular}{lc}
\hline \multicolumn{1}{c}{ COMPORTAMENTO / REQUISITOS } & NATUREZA \\
\hline Idoso apresentam dificuldade com TI & Cognitiva \\
\hline Devem ser considerados o translado de ida e vinda do idoso & Física \\
\hline Vagas de estacionamento amplas & Física \\
\hline Sinalização clara e de fácil compreensão dotadas de ilustrações & Cognitiva \\
\hline Prateleiras com alturas mais baixas para que o usuário possa ver o restante da loja & Física e Cognitiva \\
\hline Boa visão geral da loja e navegação intuitiva & Física e Cognitiva \\
\hline Espaços para repouso & Física e Social \\
\hline Agradável atmosfera de compra & Física, Cognitiva e Social \\
\hline Preços e rótulos visíveis e de fácil leitura & Cognitiva \\
\hline Chão com piso antiderrapante & Física \\
\hline Interação pessoal e amigável com o consumidor & Social \\
\hline Áreas com possibilidade para socializar com outras pessoas & Social \\
\hline Bom serviço & Social \\
\hline \multicolumn{1}{c}{ Fonte: Elaborado pelos autores, com base na pesquisa realizada. } &
\end{tabular}


Por fim, as pesquisas mostram que para os consumidores mais velhos, é importante criar ambientes comerciais eficientes e de fácil utilização, com especial atenção para os aspectos físicos e espaciais concretos da loja (Meneely, Burns e Strugnell 2009a; Meneely, Burns e Strugnell 2009b). Porém aspectos sociais também devem ser ponderados, tendo em vista que combinações de melhorias funcionais e sociais em supermercados podem resultar em consumidores fiéis, além de que alterações de design podem resultar em um ambiente de varejo adequado, especificamente concebido, que presta especial atenção à aplicação de uma abordagem social adequada, podem aumentar fortemente experiências de compras para o mercado maduro (Petermans e Van Cleempoel 2010).

\section{CONCLUSÃO}

A realização da pesquisa bibliométrica e análise dos artigos selecionados se mostrou um estudo enriquecedor e de grande utilidade para o embasamento e direcionamento de pesquisas futuras, tendo em vista que a temática ainda é pouco explorada ao redor do mundo, inclusive no Brasil. Conforme apresentado na tabela de resultados referente à revisão bibliográfica, é notável a carência de estudos relacionados à temática abordada. A produção científica dentro desse viés, ainda é pequena, e é ainda menor quando voltada para a realidade brasileira. Como fundamentado anteriormente, este novo público idoso emergente tem ganhado cada vez mais representatividade, se tornando usuários e consumidores potenciais, que possuem suas exigências, idiossincrasias, necessidades e vontades cada vez mais latentes. Contudo é um grupo a ser melhor observado, entendido explorado para que possa ser mapeado e atendido de forma mais coerente.

Outro ponto a ser observado é o fato de que todos os artigos considerados pertinentes à pesquisa são publicações recentes, sendo o mais antigo referente ao ano de 2009, o que evidencia o grau de contemporaneidade da temática. No que diz respeito às localidades onde os estudos foram realizados, se concentrando no Reino Unido, Finlândia, Bélgica e Alemanha, países esses, que nos últimos anos, têm se voltado para o estudo de serviços e a utilização de Design voltado para o desenvolvimento e melhora de serviços (KORIA, 2010).

Em relação ao projeto de supermercados de hoje, é possível perceber, com base nas análises realizadas para este estudo, que é preciso dar ênfase na funcionalidade do espaço de varejo e a forma como o ambiente de compras está organizado. No entanto, a ascensão da economia da experiência (Pine e Gilmore, 1999, 2008) deixa claro que, apesar dos benefícios óbvios da funcionalidade, acessibilidade e agradabilidade estética dos interiores comerciais, os clientes mais velhos tendem a valorizar o ambiente social de uma loja e as experiências em particular que ela pode oferecer.

Por outro lado, a identificação e delimitação das formas de consumo, necessidades, vontades e limitações do idoso em um supermercado mostra-se um excelente aliado no desenvolvimento da melhor experiência de consumo do serviço de supermercados por esse público. No entanto, as diferenças culturais resultam em diferentes experiências de compras e, finalmente, diferentes respostas do consumidor dentro do mercado para idosos (Burt e Gabbott, 1995). Por isso é preciso entender 
a realidade do consumidor idoso brasileiro em supermercados para poder perceber suas necessidades e vontades pontuais com intuito de proporcionar a melhor experiência para esse público.

Desta forma, é possível perceber que designers e varejistas de supermercados devem se esforçar para equilibrar aspectos funcionais e experienciais na concepção de espaços comerciais, sem deixar também as particularidades culturais da população idosa em questão.

\section{REFERÊNCIAS}

ABERGO - ASSOCIAÇÃO BRASILEIRA DE ERGONOMIA. Disponível em:

< http://www.abergo.org.br/internas.php?pg=o_que_e_ergonomia >. Acesso em: 15 nov. 2013.

BALAZS, A. The eldermall: exploring new ways to position theaging retail shopping center for aging consumers. Journal of Shopping Center Research, 1, 39-64. 1994.

BURT, S., \& GABBOTT, M. The elderly consumer and non-foodpurchase behaviour. European Journal of Marketing, 29(2), 43-57. 1995.

IIDA, Itiro. Ergonomia projeto e produção. São Paulo: Edgar Blucher, 1990.

JORDAN, P. W. An Introduction to Usability. Londres: Taylor \& Francis Ltda., 1998.

KIM, Y. KANG, J. KIM, M. The relationships among family and social interaction, loneliness, mall shopping motivation, and mall spending of older consumers. Psychology \& Marketing, 22(12), 995-1015. 2005.

$\mathrm{KOHIJOKI,} \mathrm{A-M.} \mathrm{The} \mathrm{effect} \mathrm{of} \mathrm{ageing} \mathrm{on} \mathrm{consumer} \mathrm{disadvantage} \mathrm{in} \mathrm{grocery} \mathrm{retail}$ services among the Finnish elderly. Journal of Retailing and Consumer Services, vol. 18, pp 370-377. 2011.

KORIA, Mikko. $\mathbf{O}$ grande valor do design é poder criar um futuro melhor. Revista Planeta, ed.459, Editora Três, São Paulo, dez. de 2010. Entrevista concedida a Cynthia Garcia. Disponível em: http://revistaplaneta.terra.com.br/secao/entrevista/quoto-grande-valor-do-design-e-poder-criar-um-futuro-melhorquot. Acessado em $22 / 01 / 2013$

MENEELY, L., STRUGNELL, C., e BURNS. Age associated changes in older consumers retail behavior. International Journal of Retail \& Distribution Management, Vol. 37 Iss: 12 , p.1041 - 1056. 2009a.

MENEELY, L., STRUGNELL, C., e BURNS, A. Elderly consumers and their food store experiences. Journal of Retailing and Consumer Services, 16, 458-465. 2009b. 
PETERMANS, A.M.S., VAN CLEEMPOEL, K. Designing a retail store environment for the mature market: a European perspective, Journal of Interior Design, Vol.35, No.2 p 21-36. 2010.

PINE, J., \& GILMORE, J. H. The experience economy: Work is theatre and every business a stage. Boston: Harvard Business School Press. 1999.

PINE, J., \& GILMORE, J. AUTHENTICITEIT. Wat consumenten echt willen. Den Haag: Academic Service. Schmidt, R., Segal, R., \& Cartwright, C. (1994). Two-stop shopping or polarization? Whither UK grocery retailing? International Journal of Retail and Distribution Management, 22(1), 12-19. 2008.

PRITCHARD, A. Statistical bibliography or bibliometrics? Journal of Documentation, v. 25, n. 4, p. 348-349. 1969.

SANTOS, Flávio Anthero dos. O Design como diferencial competitivo. Itajaí: Editora da Univali, 2000.

SILVA, Edna Lúcia da; MENEZES, Estera Muszkat. Metodologia da Pesquisa e Elaboração de Dissertação. $4^{\circ}$ edição. Florianópolis: UFSC. 2005.

SHERMAN, E., SCHIFFMAN, L., \& MATHUR, A. The influence of gender on the new-age elderly's consumption orientation. Psychology \& Marketing, 18(10), 1073-1089. 2001.

SOLOMON, M. R. Comportamento do Consumidor. 5a ed., Ed. Bookman, 2002

STREHLAU, V.I.; BACHA, M.L.; LORA, M.I. Idosos não são iguais: uma Análise de Agrupamentos Sobre as Atividades de Lazer da Terceira Idade. Anais II EMA - Encontro de Marketing da Anpad, Rio de Janeiro, 2006.

YIN, Y. PEI, E. AND RANCHHOD. The shopping experience of older supermarket consumers. Journal of Enterprise Information Management, Vol. 26 Iss: 4, pp.444 471. 2012. 